\title{
Gramágica: um jogo de fantasia para aprendizagem de classificação silábica
}

\author{
Giovanna Melo de Lima ${ }^{1}$, Jeniffer Macena de Souza ${ }^{1}$, Raquel Lais de Souza ${ }^{1}$ \\ Fernanda Pires ${ }^{1}$, Marcela Pessoa ${ }^{1}$ \\ ${ }^{1}$ Laboratório de Pesquisa e Desenvolvimento em Tecnologias Educacionais (ThinkTEd) \\ Escola Superior de Tecnologia - Universidade do Estado do Amazonas (EST/UEA) \\ Manaus - AM - Brasil \\ \{gml.lic18,jms.lic18,rls.lic18,fpires,msppessoa\}@uea.edu.br
}

\begin{abstract}
Este artigo descreve o processo de desenvolvimento de um jogo educacional chamado "Gramágica". É um jogo de aventura e fantasia para dispositivos Android, possui plataforma $2 D$ e foi desenvolvido na engine Unity, que utiliza a Linguagem de Programação C\#. O jogo tem como objetivo auxiliar na aprendizagem de um conteúdo da gramática portuguesa, referente à classificação silábica, presente na base curricular brasileira. "Gramágica" apresenta uma narrativa divertida, oferecendo um alternativa para auxiliar na aprendizagem e posterior melhoria no desempenho da disciplina Língua Portuguesa.
\end{abstract}

\section{Cenário de Uso}

Pensamento computacional (PC) refere-se a habilidades que ajudam a resolver problemas de forma otimizada, são muito exploradas na área de computação porém são necessárias a todas as áreas do conhecimento [Wing 2006]. Para resolver problemas o PC se fundamenta em quatro pilares: Decomposição, Reconhecimento de Padrões, Abstração e Algoritmo [BBC 2018]. Seguindo esta tendência, a Base Nacional Comum Curricular (BNCC) brasileira, faz menção a etapa do Ensino Fundamental, em que se precisa estimular o desenvolvimento do raciocínio lógico nos estudantes para resolução de problemas do mundo contemporâneo [MEC 2018]. Entre os conteúdos que pertencem à base de formação de qualquer país está o estudo sobre sintaxe e semântica da língua materna.

Entende-se como linguagem, qualquer sistema de signos empregado na comunicação social para expressar e comunicar ideias [Bechara 2012]. Os linguísticos notaram que a linguagem obedece regras rígidas [Koster 2013] que devem ser aprendidas por toda a população. Porém, no Brasil, dados do ENEM de 2016 apontam que apenas $34,46 \%$ dos candidatos apresentam as habilidades necessárias e exigidas para o padrão necessário do exame, especialmente no que diz respeito à escrita [INEP 2016].

Como forma de auxiliar a melhoria no cenário encontrado na disciplina de língua portuguesa, o presente trabalho propõe um jogo educacional, que se baseia nos pilares do Pensamento Computacional, com o objetivo de praticar classificação silábica. A mecânica do jogo foi combinada para que o usuário desenvolva habilidades em relação à tomada de decisão e aprendizado do conteúdo contextualizado no jogo.

"Gramágica" é um jogo destinado a dispositivos móveis, estilo plataforma, com tema de fantasia e puzzles. O público-alvo é composto por pessoas a partir de 6 anos, sem 
VIII Congresso Brasileiro de Informática na Educação (CBIE 2019)

Anais dos Workshops do VIII Congresso Brasileiro de Informática na Educação (WCBIE 2019)

limite superior de idade. O jogo tem como objetivos principais fornecer auxílio na disciplina de Língua Portuguesa e ajudar a desenvolver o Pensamento Computacional, através da formulação de estratégias para resolução de problemas encontrados na jornada. Baseado nos princípios da Teoria Cognitiva da Aprendizagem Multimídia [Mayer 2003] e na Teoria de Aprendizagem Significativa [Ausubel et al. 1980], o storytelling foi planejado para remeter o usuário a uma experiência divertida de aventura e aprendizado implícito.

\section{Desenvolvimento}

Esta seção descreve os aspectos técnicos sobre as ferramentas utilizadas no processo de desenvolvimento assim como nas respectivas etapas de design. O jogo foi desenvolvido seguindo as etapas ilustradas na Figura 1 e descritas a seguir.

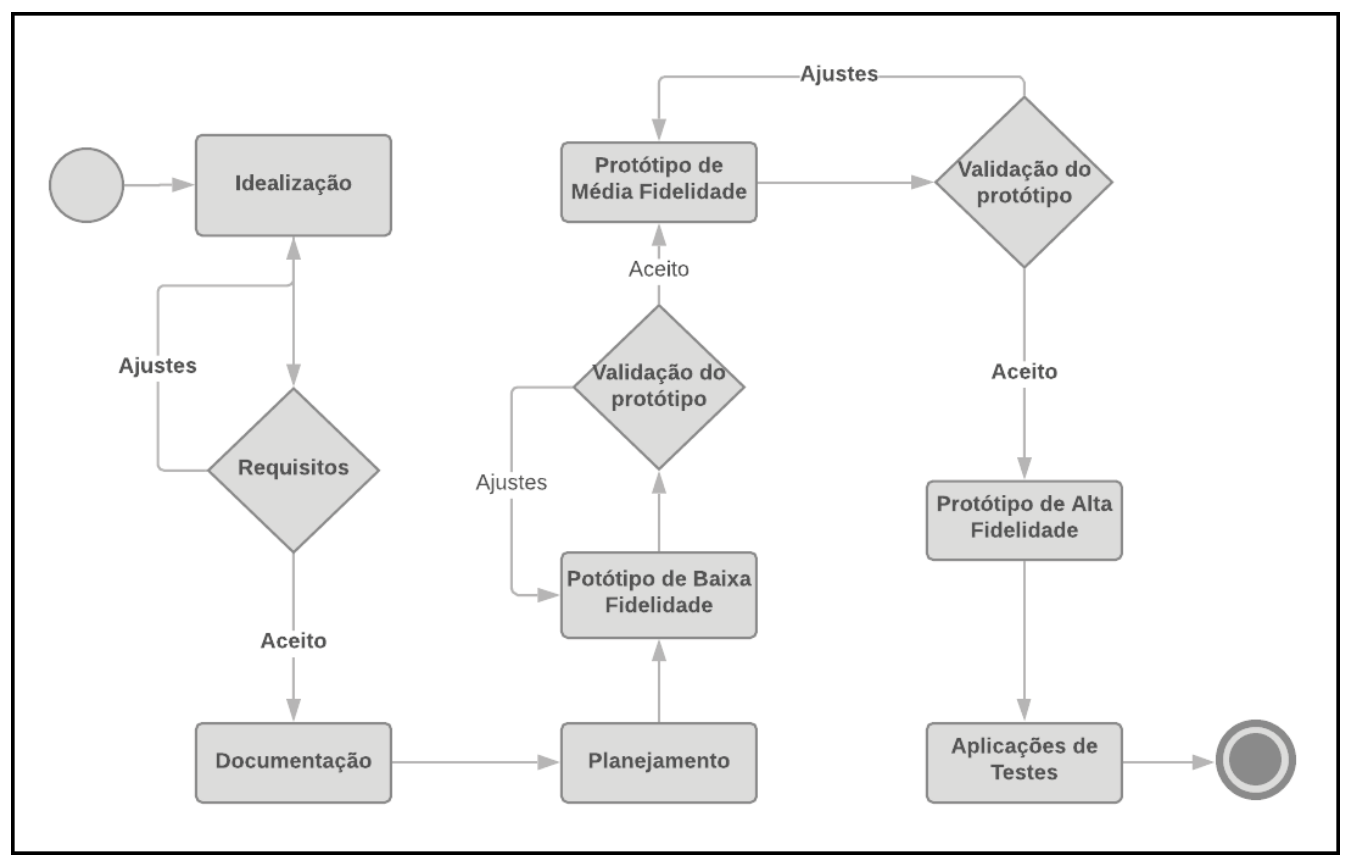

Figura 1. Fluxograma do processo de criação do Software.

- Idealização: os primeiros esboços para a ideia foram planejados nesta etapa, junto a proposta de arte a ser utilizada rascunhada, assim como: os elementos, mecânica de fases e inimigos possíveis para o formato do gameplay projetado;

- Requisitos: foram analisados os requisitos operantes e os não viáveis, além da avaliação dos aspectos teóricos e fundamentais de aprendizagem a serem incorporados na estrutura do jogo, bem como possíveis restrições de requisitos anteriores a serem ajustados.

- Documentação e Planejamento: nesta etapa houve o planejamento das atividades e a adaptação do Game Document Design (GDD). O documento descreve em seu conteúdo os elementos, a mecânica, efeitos visuais e sonoros, características presentes das fases, condições das fases e Heads-Up Display (HUD) e outros;

- Protótipo de Baixa Fidelidade: inicia-se a fase de delineamento visual e esquemático do jogo, organizando a posição de elementos e fases a serem alocados para validação posterior a sua primeira visualização; 
VIII Congresso Brasileiro de Informática na Educação (CBIE 2019)

Anais dos Workshops do VIII Congresso Brasileiro de Informática na Educação (WCBIE 2019)

- Protótipo de Média Fidelidade: seguindo as instruções do material descrito na documentação, foram implementadas as diretrizes na ferramenta de desenvolvimento Unity $2 D$, conforme foram especificadas em seu planejamento;

- Protótipo de Alta Fidelidade: a prototipação de alta fidelidade do jogo representa a versão otimizada do protótipo, levando em consideração a análise de testes e resultados validados para melhorias das funcionalidades;

- Aplicação de Testes: testes de verificação dos níveis interação e experiência das interfaces com o usuário são realizados, através das heurísticas do Teste de Usabilidade de Nielsen [Nielsen 1994], avaliando por seu intermédio o feedback de design e mecânicas propostas pelos desenvolvedores. Esta etapa está em fase de execução e ainda não tem resultados validados.

\subsection{Resumo do Estilo e Principais Referências}

Focado no público com faixa etária de 6 a 9 anos, o tema escolhido para criar o aspecto principal do jogo foi fantasia e aventura. A escolha se deu em razão dos elementos fictícios de bruxas e artefatos místicos presentes no percurso durante a jornada da heroína, em estilo "Cartoon".

Para a construção do software foram utilizadas características de outros jogos, como por exemplo Bruxa dos Acentos ${ }^{1}$, que inspirou o tema do jogo, por possuir conceitos simples de objetivo educativo relacionados ao componente curricular e Super Mario World, que inspirou o uso de plataformas e da mecânica aplicada aos "Goomba"(inimigo do Mário) para ser utilizada nas aranhas que pertencem ao cenário do jogo proposto.

\section{Apresentação do software}

"Gramágica" é um jogo em terceira pessoa, de plataforma, caracterizado por fantasia e aventura, para dispositivos móveis. Seu cenário introduz a uma ambientação fictícia de castelo, aranhas enfeitiçadas e poderosos seres mágicos. Possui nível de jogabilidade alto que permite a exploração do cenário interior do castelo.

O jogo contém atributos similares ao Super Mario World, porém seu conteúdo conecta-se com a base curricular do ensino fundamental de Língua Portuguesa de forma gamificada e se diferenciando, principalmente, pelo enredo original.

Sua visão descontraída se distribui sob aspectos interativos através de animações e cores atrativas. "Gramágica" se propõe a relacionar os elementos de jogos com os de aprendizagem de forma implícita. No cenário, estão dispostas metas (ou missões), como ilustrado na Figura 2 (a) a serem cumpridas de forma a alcançar o objetivo final. Dessa forma, o progresso da aprendizagem sobre a classificação das palavras está ligada à jornada da heroína que deve avançar até a torre mais alta, como ilustrado na Figura 2 (b) e cumprir o seu objetivo final através do boss fight.

Resumidamente, quando a heroína percorre o cenário é surpreendida por aranhas, como ilustrado nas Figuras 3 (a) e (b). Algumas aranhas são especiais e quando a heroína pula sobre elas surge um conjunto de palavras, dependendo da fase as palavras exploradas mudam de classificação, podendo ser monossílabas, como ilustrado na Figura 3 (c), dissílabas, conforme apresentado na Figura 3 (d) ou trissílabas. O objetivo de cada fase

\footnotetext{
${ }^{1}$ http://www.escolagames.com.br/jogos/bruxaDosAcentos/
} 
VIII Congresso Brasileiro de Informática na Educação (CBIE 2019)

Anais dos Workshops do VIII Congresso Brasileiro de Informática na Educação (WCBIE 2019)

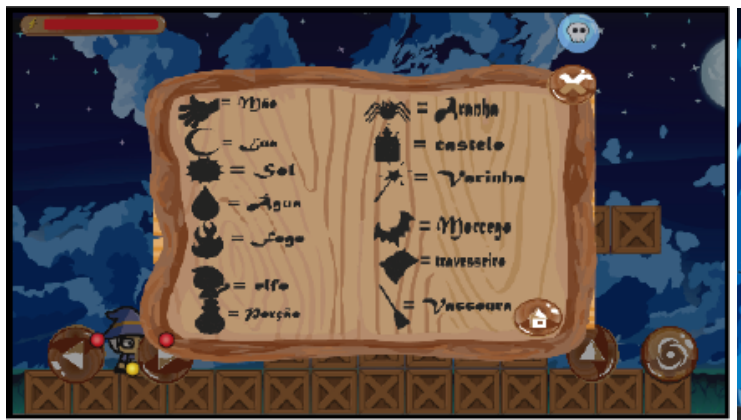

(a) Placa de missões

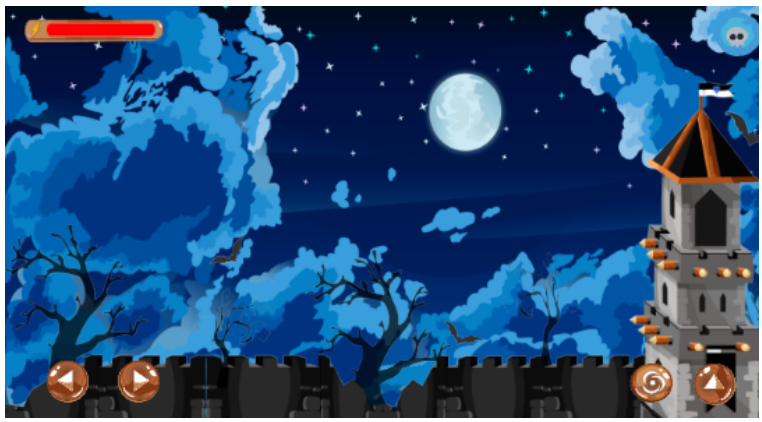

(b) Fase final.

Figura 2. Conjunto de palavras que a heroína tem como missão encontrar e a imagem que representa a fase final.

é encontrar um conjunto de palavras que juntas serão usadas para desbloquear a próxima fase, definidas na placa de missão. Para garantir o elemento sorte no jogo algumas aranhas não são especiais e servem unicamente para fazer com que a heroína lute contra a aranha e evite perder vidas.

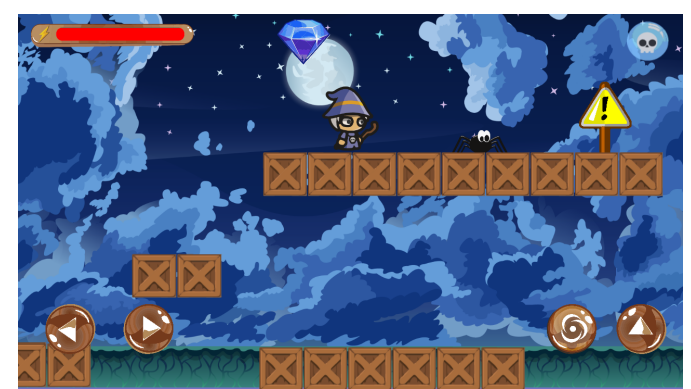

(a) Momento em que a heroína encontra a ara- (b) nha na Fase 1.

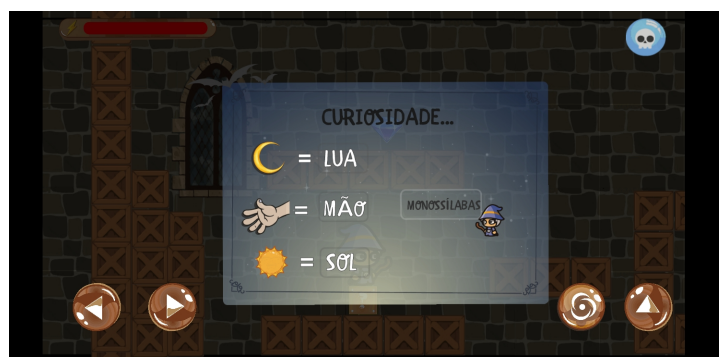

(c) Palavras monossílabas

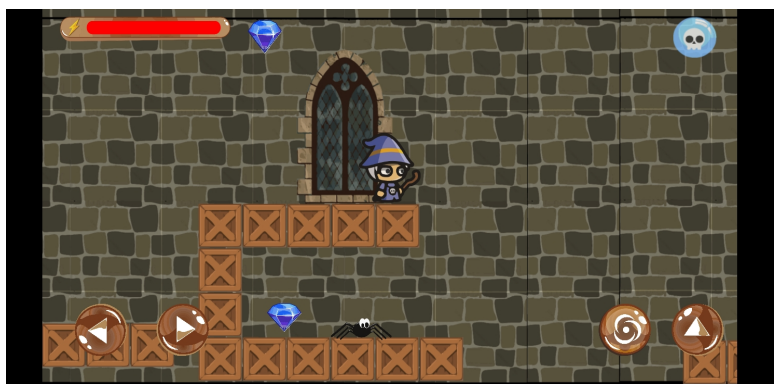

(b) Momento em que a heroína encontra a aranha na Fase 2.

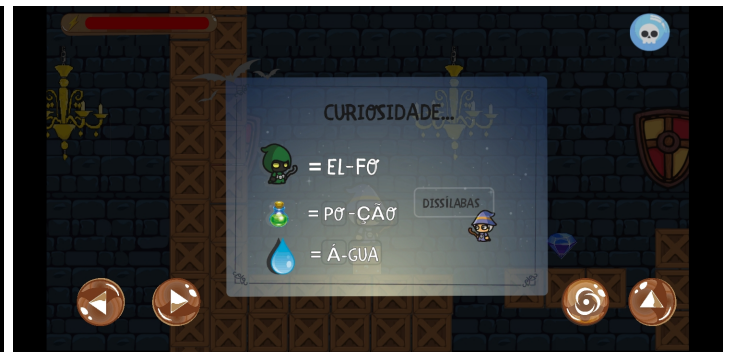

(d) Palavras dissílabas

Figura 3. llustração do encontro da aranha com a heroína (a) e (b) e o que acontece no jogo após a heroína encontrar e pular sobre uma aranha especial. Dependendo da fase serão apresentadas palavras de classes diferentes, como monossílabas (c) e dissílabas (d).

\subsection{Personagens}

A personagem principal, Granger, é semelhante a uma criança com o estilo de uma pequena bruxa. A Figura 4 apresenta Granger, que possui um cajado, coletado pelo jogador e que pode ser trocado no decorrer da transição de fases. 
VIII Congresso Brasileiro de Informática na Educação (CBIE 2019)

Anais dos Workshops do VIII Congresso Brasileiro de Informática na Educação (WCBIE 2019)

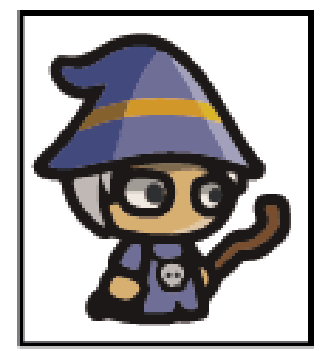

Figura 4. Personagem principal (Granger).

\subsection{Inimigos}

Em relação ao estilo e tema do jogo, o mago Rusbel está no ultimo andar do castelo, acompanhado da mãe de Granger, que está presa como refém de seu plano macabro. O castelo está enfeitiçado, assim como os animais que vivem dentro dele (aranhas) e seus aprendizes. A Figura 5 ilustra os inimigos, que neste caso são as aranhas, os aprendizes e o mago Rusbel.

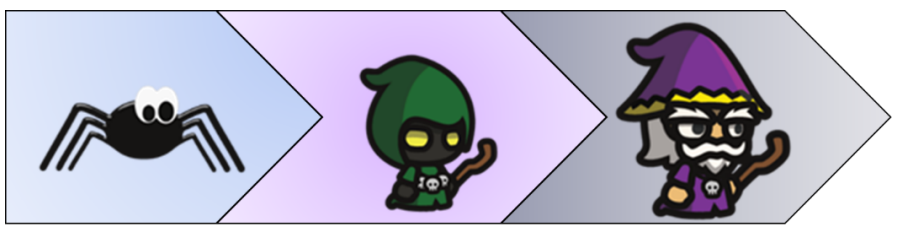

Figura 5. Inimigos.

\subsection{Cenários}

Os cenários representam andares de diferentes níveis no interior do castelo. Sendo previstos 4 andares e 1 cenário para fase final, no seu topo. A fase de tutorial (Figura 6 (a) possui exclusivamente o cenário externo e aberto, com a lua em seu centro, seguido por organização de plataformas, armadilhas e desafios (Figura 6 (b)) que indicam ao jogador como usar os ícones necessários durante as fases para indicar a preparação da personagem antes de enfrentar os inimigos do castelo.

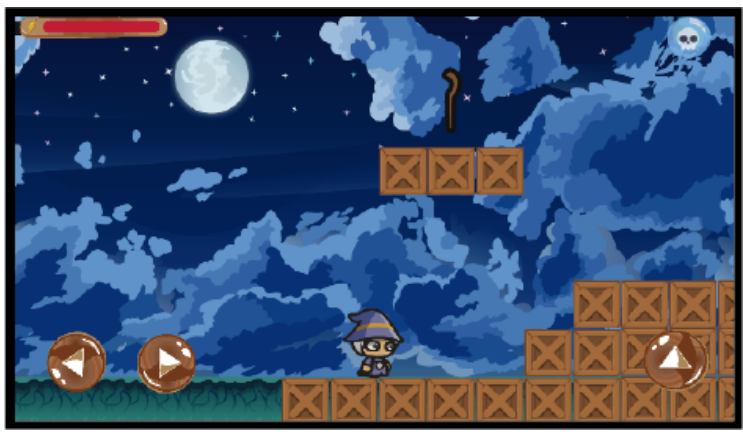

(a)

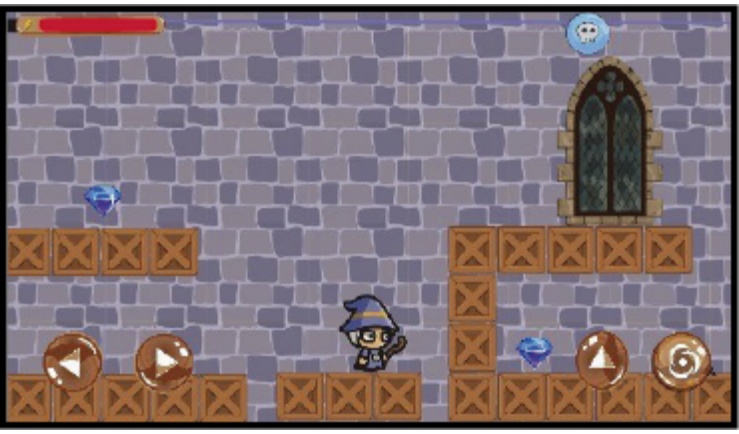

(b)

Figura 6. (a) Itens encontrados na fase tutorial. (b) Desafios encontrados na primeira fase. 
VIII Congresso Brasileiro de Informática na Educação (CBIE 2019)

Anais dos Workshops do VIII Congresso Brasileiro de Informática na Educação (WCBIE 2019)

\subsection{H.U. D (Head Up Display)}

O conjunto de HUD é apresentado na figura 7 e é composto por:

- Barra de energia: ilustra o nível de energia do jogador ao receber ataque dos inimigos. A energia diminui gradativamente até que a personagem fique cansada e impossibilitada de prosseguir seu percurso;

- Pingente mágico: exibe as palavras a serem coletadas junto com as imagens que sugerem seu sentido figurativo;

- Diamantes: conforme coletados, ficam visíveis ao lado da barra de energia.

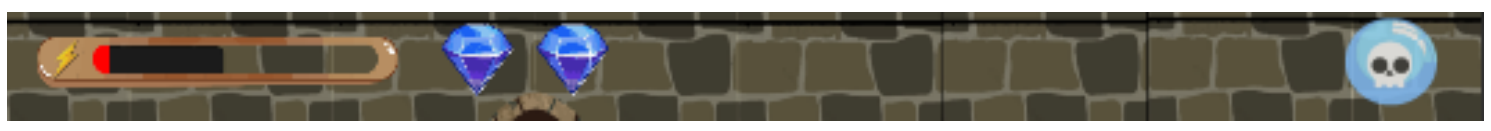

Figura 7. H.U.D. do jogo.

\section{Aprendizagem e desenvolvimento do Pensamento Computacional}

O jogo Gramágica trabalha com os pilares do Pensamento Computacional e com a visualização do objetivo da fase junto aos inimigos presentes nas plataformas, coexistindo a necessidade de quebrar problema em partes pequenas para planejar como avançar em sua missão (Decomposição) [Liukas 2015]; no decorrer das fases é essencial observar similaridades entre os cenários para cumprir os requisitos de forma mais eficiente (Reconhecimento de padrões) [Liukas 2015]; durante a busca dos elementos especiais e coletáveis o usuário classifica suas prioridades, como por exemplo, buscar as palavras para cumprir a tabela e ignorar inimigos que não agregam ao personagem (Abstração); logo o usuário já visualiza como planejar seus passos para completar o objetivo principal e resgatar a mãe da personagem, assim como reunir as peças soltas para fase final do jogo.

O jogo trabalha o componente curricular de Língua Portuguesa.Visto que, de acordo com a Base Nacional Comum Curricular (BNCC) são abordados conteúdos referentes à formação silábica desde os princípios da alfabetização no Ensino Fundamental I, enfatizando o conteúdo durante o $3^{\circ}$ ano.

\section{Considerações finais}

O jogo "Gramágica" foi desenvolvido para auxiliar na aprendizagem do conteúdo de Língua Portuguesa de forma lúdica. O foco principal do jogo são conteúdos relacionados à separação silábica.

O jogo une elementos de um jogo do tipo puzzle com jogos de plataforma alinhados de maneira a gerir um ciclo de aprendizagem para a classificação silábica. A mecânica e gameplay do jogo propiciam um cenário em que são exercitados os 04 pilares do Pensamento computacional (decomposição, padrão, abstração eté a criação do algoritmo que solucionará o problema apresentado).

Futuramente pretende-se realizar testes externos, aplicados para avaliar o nível de interesse e grau de usabilidade através da experiência do jogador, por meio de heurísticas do método conhecido como Game Flow e propor novas fases que abordem contextos mais complexos. 
VIII Congresso Brasileiro de Informática na Educação (CBIE 2019)

Anais dos Workshops do VIII Congresso Brasileiro de Informática na Educação (WCBIE 2019)

\section{Referências}

Ausubel, D. P., Novak, J. D., and Hanesian, H. (1980). Psicologia educacional. Interamericana.

BBC (2018). Ks3 bitesize computer science: Introduction to computational thinking.

Bechara, E. (2012). Moderna gramática portuguesa. Nova Fronteira.

INEP (2016). Resultados da ana 2016 por estados e municipios estao disponiveis no painel educacional do inep.

Koster, R. (2013). Theory of fun for game design. "O'Reilly Media, Inc.".

Liukas, L. (2015). Hello Ruby: adventures in coding, volume 1. Macmillan.

Mayer, R. (2003). The promise of multimedia learning: using the same instructional design methods across different media. 13(2):125-139.

MEC (2018). Ministerio da educacao - base nacional comum curricular.

Nielsen, J. (1994). Usability engineering. Elsevier.

Wing, J. (2006). Computational thinking. 49(3):33-35. 